\title{
Dog ownership, dog walking, and social capital
}

\author{
Mohammad Javad Koohsari (1, 2,3凶 ${ }^{\text {, Akitomo Yasunaga }}{ }^{4}$, Ai Shibata ${ }^{5}$, Kaori Ishii ${ }^{1}$, Rina Miyawaki ${ }^{6}$, \\ Kuniko Araki ${ }^{1}$, Tomoki Nakaya ${ }^{7}$, Tomoya Hanibuchi ${ }^{7}$, Gavin R. McCormack ${ }^{1,8,9,10}$ \& Koichiro Oka ${ }^{1}$
}

Evidence for social pathways to health benefits for dog owners appears positive but less welldeveloped. Our study aimed to estimate the differences in social capital by dog ownership and dog walking status among young-to-middle-aged adults and older adults in Japan. Data from 3606 residents living in Japan were used. Data on social capital, dog ownership, and dog walking were collected by questionnaires. Age-stratified multivariable linear regression models were used to estimate differences in social capital scores by dog ownership and dog walking status. Among young-to-middle-aged adults, the mean of the activities with neighbours score, adjusted for covariates, was significantly higher $(p<0.05)$ for the dog owner walkers group compared to the non-dog owners group. Among older adults, no significant differences in the marginal means of social capital scores were observed between the three groups of non-dog owners, dog owner non-walkers, and dog owner walkers. While the benefits of social capital for a healthy lifestyle have been well-documented, few means have been identified to intervene in social capital. Building on and expanding the known health benefits of dog ownership and dog walking, this study revealed modest support for the link between dog walking and activities with neighbours among young-to-middle-aged adults, but no meaningful associations were found for older adults. Additionally, no significant link was observed between dog walking and social cohesion among either age group. Future research can further improve the use of dog-based behavioural health interventions for fostering social capital.

\footnotetext{
${ }^{1}$ Faculty of Sport Sciences, Waseda University, Tokorozawa, Saitama, Japan. ${ }^{2}$ Melbourne School of Population and Global Health, The University of Melbourne, Melbourne, Victoria, Australia. ${ }^{3}$ Behavioural Epidemiology Laboratory, Baker Heart and Diabetes Institute, Melbourne, Victoria, Australia.

${ }^{4}$ Faculty of Liberal Arts and Sciences, Bunka Gakuen University, Shibuya, Tokyo, Japan. ${ }^{5}$ Faculty of Health and Sport Sciences, University of Tsukuba, Tsukuba, Ibaraki, Japan. ${ }^{6}$ School of Arts and Letters, Meiji University, Suginami, Tokyo, Japan. ${ }^{7}$ Graduate School of Environmental Studies, Tohoku University, Sendai, Miyagi, Japan. ${ }^{8}$ Department of Community Health Sciences, Cumming School of Medicine, University of Calgary, Calgary, AB, Canada. ${ }^{9}$ Faculty of Kinesiology, University of Calgary, Calgary, AB, Canada. ${ }^{10}$ School of Architecture, Planning and Landscape, University of Calgary, Calgary, AB, Canada. ${ }^{凶}$ email: javadkoohsari@aoni.waseda.jp
} 


\section{Introduction}

large number of people worldwide are living with a pet, particularly dogs. For example, $17 \%$ of households in Japan own a dog (Growth from Knowledge, 2016). Even higher dog ownership was reported in Canada and the U.S., where 35 and $48 \%$ of households have a dog (American Pet Products Association, 2018; Canadian Veterinary Medical Association, 2011). Given the prevalence of dogs in households, dog ownership has drawn increasing interest in public health research and practice.

Mounting evidence has shown the positive health-related outcomes of having a dog as a companion (Barcelos et al., 2020; Koohsari et al., 2020b; Mubanga et al., 2017; Westgarth et al., 2019). Notably, several studies have highlighted dog walking as a key pathway through which dog ownership may support health. For example, a study in the U.S. found that dog walking was associated with more frequent moderate to vigorous exercise (e.g., gardening, walking at a moderate pace, running, swimming, playing tennis) among a nationally representative sample of older adults (Curl et al., 2016). A study in Japan revealed that dog owners were 1.5 times more likely to meet a physical activity recommendation (as engaging in 23 or more metabolic equivalent tasks [in hours per week] of physical activity) than non-dog and non-pet owners (Oka and Shibata, 2009). A multisite, international study showed that dog walkers were more likely to achieve $\geq 30$ min of moderate to vigorous physical activity on more days of the week than non-dog walkers (Christian et al., 2016). Several reviews have demonstrated consistent evidence for positive associations between dog ownership, dog walking, and physical activity (Cutt et al., 2007; Rock et al., 2015; Toohey and Rock, 2011); evidence for other pathways to health benefits for owners appears positive, but less well-developed (Christian et al., 2018).

Notably, social capital may be one potential pathway to explain the positive health benefits of owning a dog and dog walking. Several studies and systematic reviews have confirmed that fostering social capital confers several physical and mental health issues (Fujisawa et al., 2009; Mackenbach et al., 2016; RiumalloHerl et al., 2014; Rodgers et al., 2019; Wang et al., 2009; Xue et al., 2020; Yip et al., 2007). For instance, a study conducted in five urban regions in Belgium, France, Hungary, the Netherlands and the U.K. found that higher social capital constructs, including social networks and social cohesion, were associated with better physical health outcomes, including self-rated health and weight status (Mackenbach et al., 2016). A study carried out in Chile indicated that higher social support, generalised trust and neighbourhood trust were associated with lower depression and a better cardiovascular disease risk factor profile (Riumallo-Herl et al., 2014). Another study performed in China revealed that social capital was associated with better self-reported general health, psychological health, and subjective well-being among a rural population sample (Yip et al., 2007). Some previous studies have observed age differences in the link between social capital and health benefits (Muckenhuber et al., 2013; Nyqvist et al., 2016; Pan, 2018). A study conducted in Austria found that social capital affects older adults' health more strongly than younger individuals (Muckenhuber et al., 2013). Another study carried out in an Asian context witnessed an age difference in the associations between social capital indicators and the life satisfaction of elderly Chinese people living in rural areas (Pan, 2018). They found that the effects of trust and activity frequency on life satisfaction decreases as participants' age increases (Pan, 2018).

Dogs may also act as catalysts for social interactions, which may subsequently foster social capital (McNicholas and Collis, 2000; Wells, 2004). Social capital generally refers to the resources and benefits available to individuals or groups through their social connections (Kawachi, 2010). There are two streams of social capital theory: the 'communitarian approach' and the 'network approach' (Moore et al., 2006). The former has been predominantly used in public health studies. Moore et al. (2006) noted the differences between two streams of social capital: 'whereas communitarian approaches examine the effects of civic participation and trust on health, network approaches analyse relational dimensions of solidarity, highlighting the influence of social structure, power, and disparities in access to resources on health' (page 729). Both approaches may be necessary for understanding the link between social capital and health (Kawachi et al., 2008; Rodgers et al., 2019). Few empirical studies have examined the associations among dog ownership, dog walking, and social capital, much of which appears to be limited to Australian, U.S., and Canadian populations (Curl et al., 2020; Graham and Glover, 2014; Wood et al., 2017). For instance, a study performed in the U.S. and Australia showed that owning a pet (including dog ownership) was associated with better social capital (Wood et al., 2017). Another study conducted in the U.S. scrutinised the associations among dog ownership, dog walking, social interactions, and life satisfaction among older adults and discovered that the amount of dog walking was positively associated with the frequency of social contact (Curl et al., 2020). Another study conducted in Canada using qualitative data examined whether dogs may facilitate or impede building social relationships among dog owners in dog parks (Graham and Glover, 2014). They found that the ways dogs act towards other dogs and humans can positively or negatively impact their owners' social capital (Graham and Glover, 2014). Nevertheless, the evidence thus far has been limited to Australia, the U.S., and Canada. Like Western nations (American Pet Products Association, 2018; Canadian Veterinary Medical Association, 2011), the prevalence of dogs in households is significant in Asian countries such as Japan (17\%), China (20\%), and South Korea (20\%) (Growth from Knowledge, 2016). Exploring dog ownership and social capital relationships in different cultural and geographic contexts is necessary as different cultural norms may shape dog walking practices (Degeling and Rock, 2013; Westgarth et al., 2014). Compact built environments in Asia, characterised by ultrahigh population density and efficient public transport systems, are significantly different compared to the sprawled, lower density of Western areas (Koohsari et al., 2018). Variations in urban design attributes and conventions across different places may, therefore, influence owning a dog and dog walking, such as waste removal rules, the provision of dog parks, and public spaces where dogs are allowed to run free (Koohsari et al., 2020a; Westgarth et al., 2014). Hence, future research in different cultural and geographic contexts can shed light on whether dog owners and dog walkers may benefit from having more robust social capital than non-dog owners.

As a first study conducted in an Asian context, our aim was to estimate the differences in social capital by dog ownership and dog walking status among young-to-middle-aged adults and older adults in Japan. The research hypotheses are as follows: (a) dog ownership and dog walking are significantly positively associated with social capital scores, and (b) these associations may differ by age group.

\section{Methods}

Data source and participants. Our analysis included crosssectional data from an epidemiological study that was undertaken to examine correlates of health behaviours and outcomes among residents living in the town of Minami-Izu in Japan's Shizuoka Prefecture. Minami-Izu is located approximately $138 \mathrm{~km}$ 
southwest of Tokyo, with about 8100 residents in 2020, living mainly in single-family detached dwellings. Data were obtained between October and November 2016 from all adults (aged over 20 years old) living in Minami-Izu. A self-administered questionnaire was distributed by research staff to all adult residents $(n=7360)$, except for those who were hospitalised and bedridden or institutionalised. The questionnaires were collected after two to three weeks. A total of 4714 residents (response rate $=73.6 \%$ ) agreed to participate and returned the completed questionnaires. The Waseda University Research Ethics Committee (Japan) approved the study (2016-280).

\section{Measures}

Social capital. Two social capital scores, social cohesion and activities with neighbours, were assessed by the related items developed by Mujahid et al. (2007). Although not explicitly stated in Mujahid et al. (2007), each score was considered to roughly correspond to the communitarian and network definitions of social capital. According to Bassett and Moore (2013), communitarian approaches typically focus on psychosocial or cognitive constructs (e.g., perceptions of trust or cohesion), while network approaches directly measure individuals' social connections and the resources available within the networks. In this study, social cohesion was measured using the following four items (Cronbach's alpha $=0.88$ ) to which participants responded on a Likerttype scale ranging from 1 (strongly agree) to 5 (strongly disagree): 'People around here are willing to help their neighbours', 'People in my neighbourhood generally get along with each other', 'People in my neighbourhood can be trusted', and 'People in my neighbourhood share the same values'. The following five items (Cronbach's $\alpha=0.84$ ) were used to calculate activities with neighbours: 'About how often do you and people in your neighbourhood do favours for each other? By favours, we mean such things as watching each other's children, helping with shopping, lending garden or house tools, and other small acts of kindness'; 'When a neighbour is not at home or on vacation, how often do you and other neighbours watch over their property'?; 'How often do you and other people in the neighbourhood ask each other for advice about personal things such as child-rearing or job openings'?, 'How often do you and people in your neighbourhood have parties or other get together where other people in the neighbourhood are invited'? and 'How often do you and other people in your neighbourhood visit each other's homes or speak with each other on the street'? The participants answered these items on a Likert-type scale ranging from 1 (often) to 4 (not at all). Social cohesion and activities with neighbours were calculated as the means of these four and five items, respectively. The response categories were reverse coded so that higher scores indicated higher social cohesion and activities with neighbours. The internal consistencies were almost the same for the two age categories of 20 to 64 years old and at least 65 years old (Cronbach's $\alpha>0.80$ ).

Dog ownership and dog walking status. The participants were asked if they currently owned a pet in their household. Those who responded 'Yes' reported the type of pet, including dogs, cats, and others (e.g., birds, fish, and reptiles). Dog owners also responded to the question, 'In a usual week, do you walk with your dog(s)'? If they answered 'Yes', owners were asked to report the weekly frequency and minutes of their dog walking. These items have good reliability and have been used in previous studies (Cutt et al., 2008; Liao et al., 2018; Shibata et al., 2012). Dog walkers were defined as dog owners who walked their dogs for at least 10 min per week (Oka and Shibata, 2012; Shibata et al., 2012). Dog ownership and dog walking were combined into three groups: (a) non-dog owners, (b) dog owner non-walkers, and (c) dog owner walkers.

Covariates. The participants reported their age, gender (female and male), education level (tertiary or higher, below tertiary), marital status (single or married), and length of residence at their current address.

Statistical analysis. Descriptive statistics, including frequencies and measures of central tendency and variation, were calculated for sociodemographic, dog ownership, dog walking, and social capital (social cohesion and activities with neighbours) scores. An age-stratified analysis was performed using two age groups of 20 to 64 years old and at least 65 years old, given that social capital and walking abilities can vary significantly across age groups (Corder et al., 2009; McDonald and Mair, 2010). Pearson's chisquare test and independent $\mathrm{t}$-tests were used to compare sociodemographic, dog ownership, dog walking, and social capital variables between these two age groups. One-way analysis of variance (ANOVA) was used to compare social capital scores between non-dog owners, dog owner non-walkers, and dog owner walkers. Age-stratified multivariable linear regression models were used to estimate differences in social capital scores by dog ownership and dog walking status (20 to 64 years old and at least 65 years old). All models were adjusted for sociodemographic variables. Linear regression estimates were reported as marginal means (with $95 \%$ confidence intervals). Tukeyadjusted, pairwise comparisons among non-dog owners, dog owner non-walkers, and dog owner walkers were conducted when group differences from ANOVA and linear regression tests were statistically significant $(p<0.05)$. The analyses were carried out using Stata 15.0 (Stata Corp, College Station, Texas).

\section{Results}

This analysis included complete data from 3606 participants. No significant differences in any of the variables were observed between those with missing data and those with complete data. Table 1 shows the characteristics of the study sample. Approximately $53 \%$ of the sample were female $(n=1912)$, around $34 \%$ had a high tertiary educational attainment $(n=1227)$, and approximately $78 \%$ were married $(n=2801)$, with a mean length of residence of $33.5 \pm 22.3$ years. Our sample included 507 (14.1\%) dog owners, of which 282 participants (55.6\%) walked their dog for at least $10 \mathrm{~min}$ per week. Approximately $52 \%$ of the participants were aged 20 to 64 years old (young-to-middle-aged adults), and about $48 \%$ were at least 65 years old (older adults). Some differences in sociodemographic characteristics, dog ownership and dog walking status, and social capital scores between young-to-middle-aged adults and older adults were found (Table 1). Table 2 displays the social capital mean scores among the nondog owners, dog owner non-walkers, and dog owner walkers groups. The mean score of activities with neighbours was significantly higher among dog owner walkers than dog owner nonwalkers $(p<0.05)$. No other significant differences were detected in the social capital scores among the non-dog owners, dog owner non-walkers, and dog owner walkers groups.

Table 3 presents the outcomes of the age-stratified, adjusted linear regression estimates (marginal means) for differences in social capital scores by dog ownership and dog walking status. No significant differences in the marginal means of social cohesion score were noted between the three groups of non-dog owners, dog owner non-walkers, and dog owner walkers among either young-to-middle-aged adults or older adults. Among young-tomiddle-aged adults, the mean of the activities with neighbours score, adjusted for covariates, was significantly higher $(p<0.05)$ 
Table 1 Characteristics of the study participants $(N=3606)$.

\begin{tabular}{|c|c|c|c|}
\hline \multirow[t]{2}{*}{ Variable } & \multicolumn{3}{|c|}{ N (\%) or Mean (S.D.) } \\
\hline & Total & $\begin{array}{l}20 \text { to } 64 \\
\text { years old } \\
(n=1884)\end{array}$ & $\begin{array}{l}\text { At least } 65 \\
\text { years old } \\
(n=1722)\end{array}$ \\
\hline \multicolumn{4}{|l|}{ Gender } \\
\hline Female & $1912(53.0)$ & $970(51.5)$ & $942(54.7)$ \\
\hline Male & $1694(47.0)$ & 914 (48.5) & $780(45.3)$ \\
\hline \multicolumn{4}{|l|}{ Education levela } \\
\hline $\begin{array}{l}\text { Tertiary } \\
\text { or higher }\end{array}$ & $1227(34.0)$ & $896(47.6)$ & $331(19.2)$ \\
\hline \multicolumn{3}{|l|}{ Marital status ${ }^{a}$} & $1391(80.8)$ \\
\hline Single & $805(22.3)$ & $551(29.2)$ & $254(14.8)$ \\
\hline Married & $2801(77.7)$ & $1333(70.8)$ & $1468(85.2)$ \\
\hline $\begin{array}{l}\text { Length of } \\
\text { residence }\end{array}$ & $33.5(22.3)$ & $24.1(17.6)$ & $43.3(22.7)$ \\
\hline \multicolumn{4}{|c|}{ Dog ownership/dog walkinga } \\
\hline $\begin{array}{l}\text { Non- } \\
\text { dog owners }\end{array}$ & $3099(85.9)$ & $1582(84)$ & $1517(88.1)$ \\
\hline $\begin{array}{l}\text { Dog owner non- } \\
\text { walkers }\end{array}$ & $225(6.2)$ & $153(8.1)$ & $72(4.2)$ \\
\hline $\begin{array}{l}\text { Dog owner } \\
\text { walkers }\end{array}$ & $282(7.8)$ & $149(7.9)$ & $133(7.7)$ \\
\hline Social cohesion & $3.6(0.7)$ & $3.6(0.7)$ & $3.6(0.7)$ \\
\hline $\begin{array}{l}\text { Activities with } \\
\text { neighbours }\end{array}$ & $2.2(0.6)$ & $2.1(0.6)$ & $2.3(0.6)$ \\
\hline
\end{tabular}

aStatistically significant difference $(p<0.05)$ based on Pearson's chi-square or $t$-test. Social capital: $\min =1$, $\max =5$; Activities with neighbours: $\min =1$, $\max =4$; Higher scores indicate more social cohesion and more activities with neighbours.

for the dog owner walkers group than for the non-dog owners group. No significant differences in the marginal means of activities with neighbours score were found between dog owner walkers and dog owner non-walkers. Among older adults, there were no significant differences in the marginal means of activities with neighbours among the three groups of the non-dog owners, dog owner non-walkers, and dog owner walkers.

\section{Discussion}

The purpose of our study was to determine the extent to which dog ownership and dog walking status were associated with measures of social capital for young-to-middle-aged adults and older adults living in Japan. Overall, we found that young-tomiddle-aged adult dog owners who walked their dogs had a notably higher score of activities with neighbours than non-dog owners. Our findings with Japanese adults are consistent with previous studies conducted in Australia and the U.S., which showed that dog walkers reported higher social capital scores than non-dog owners (Wood et al., 2017). Notably, significant differences in social capital by dog ownership walking status were only detected for young-to-middle-aged adults and only for activities with neighbours.

There are several possible explanations for our novel findings. Walking with a dog may facilitate interactions with neighbours since dogs may act as catalysts to initiate casual conversations (McNicholas and Collis, 2000; Rogers et al., 1993; Wood et al., 2015). For example, in a park setting, dog walkers were more likely to have conversations with others than non-dog owners (Wood and Christian, 2011). Dog walkers may also be more recognisable to others within their neighbourhoods (Power, 2013). A qualitative study of dog owners who lived in apartments in Australia found that dogs can act as identifying devices making their owners noticeable within their communities (Power, 2013). Our findings add to the literature and extend it to the context of
Table 2 Social capital scores among the non-dog owners, dog owner non-walkers, and dog owner walkers groups.

\begin{tabular}{lll} 
& \multicolumn{2}{l}{ Mean (S.D.) } \\
\cline { 2 - 3 } & Social cohesion & $\begin{array}{l}\text { Activities with } \\
\text { neighbours }\end{array}$ \\
\hline $\begin{array}{l}\text { Non-dog owners } \\
(n=3099)\end{array}$ & $3.56(0.68)$ & $2.19(0.65)$ \\
$\begin{array}{l}\text { Dog owner non- } \\
\text { walkers } \\
(n=225)\end{array}$ & $3.62(0.64)$ & $2.12(0.66)^{a}$ \\
$\begin{array}{l}\text { Dog owner walkers } \\
(n=282)\end{array}$ & $3.55(0.56)$ & $2.27(0.57)^{\text {a }}$ \\
\hline $\begin{array}{l}\text { aEstimates with the same letter superscript (a) are significantly different between groups at } p< \\
\text { 0.05. } \\
\text { Social capital: min }=1, \text { max }=5 \text {; Activities with neighbours: min }=1, \text { max }=4 \text {; Higher scores } \\
\text { indicate more social cohesion and more activities with neighbours. }\end{array}$ \\
\hline
\end{tabular}

Asia, where the number of pet owners is rising (Spire Research and Consulting, 2018).

No significant differences in social capital scores were observed between young-to-middle-aged adults' dog owner walkers and dog owner non-walkers. Our results highlight the importance of dog walking as a possible pathway through which some social benefits of dog ownership may be conveyed among young-tomiddle-aged adults. Nevertheless, not all dog owners walk their dogs: in our sample, $\sim 44 \%$ of dog owners (51\% of young-tomiddle-aged adult dog owners) did not report walking their dog. Several personal, social, and urban design factors may influence dog owners' decision to walk their dogs (Christian et al., 2017). Future research can explore how these factors can affect adults' social capital by changing their dog walking levels.

Among older adults, no significant differences in social capital scores-regardless of the indicators used (social cohesion or activities with neighbours)-were noted among the three groups of non-dog owners, dog owner non-walkers, and dog owner walkers. This outcome contrasts with a previous qualitative study that revealed positive effects of dog ownership and dog walking on older adults' social capital (Hui Gan et al., 2019). In a study among older adults, Hui Gan et al. (2019) discovered that pets (mainly dogs) provide their owners with opportunities to be more socially connected with society. Our finding also contrasts with a prior study carried out in Canada that found that frequent older dog walkers were more likely to report a higher sense of community than non-owners (Toohey et al., 2013). While this sense of community is conceptually distinct from social capital, it draws on similar dimensions of social capital (e.g., trust in neighbours) (Wood et al., 2005) and can be a correlate of social capital (Pooley et al., 2005). The exact reasons for these null findings on associations between dog ownership, dog walking, and social capital among the elderly in our study are unclear. The use of different instruments to measure social capital in past studies may be a reason for the disagreement in the findings. Further, older Japanese adults had an opportunity to build strong connections within their residential communities due to prolonged stays in their neighbourhoods and cultural attitudes (Hanibuchi et al., 2012). More research is needed to confirm these findings.

This study has some limitations. The self-reported measures of dog walking are subject to recall bias. As a cross-sectional study, we were unable to draw causal relationships between variables. A perceived lack of social cohesion and the ability to ask neighbours for favours and initiate communications with them might also impact the decision to have a dog or walk one's dog. Future studies should also control for these items. The non-specificity of 
Table 3 Age-stratified adjusted linear regression estimates (marginal means) and 95\% confidence intervals for differences in social capital scores by dog ownership and dog walking status.

\begin{tabular}{|c|c|c|c|c|}
\hline & \multicolumn{2}{|l|}{ Social cohesion } & \multicolumn{2}{|l|}{ Activities with neighbours } \\
\hline Non-dog owners & $3.55(3.51,3.58)$ & $3.56(3.53,3.60)$ & $2.08(2.05,2.11)^{a}$ & $2.30(2.27,2.33)$ \\
\hline Dog owner non-walkers & $3.65(3.54,3.75)$ & $3.57(3.42,3.73)$ & $2.07(1.97,2.18)$ & $2.27(2.13,2.41)$ \\
\hline Dog owner walkers & $3.61(3.50,3.71)$ & $3.55(3.43,3.66)$ & $2.24(2.14,2.34)^{a}$ & $2.32(2.21,2.42)$ \\
\hline
\end{tabular}

social capital items to dog ownership status may be another limitation. Graham and Glover (2014) illustrated how dog-dog, dog-people, and people-people interactions influenced dog owners' social relations. Future studies should develop dog-related social capital items and explore various dog-people interactions in relation to social capital. Only dogs were included in this study. More research is needed to find the social capital benefits of other types of pets. This study was conducted in a small town in Japan with few variations in urban design features and relatively the same rules related to dog walking (e.g., dogs must be kept on a leash, one must clean up after one's dogs). More studies in a diverse geographic and social context are required to explore how urban design and social determinants of dog walking may impact social capital (Christian et al., 2018). The large representative sample and the focus on the less-studied geographic context of Asia are strengths of this study.

\section{Conclusions}

While the benefits of social capital for a healthy lifestyle have been well-documented, few means have been identified to intervene in social capital. Building on and expanding the known health benefits of dog ownership and dog walking, this study revealed modest support for the link between dog walking and activities with neighbours among young-to-middle-aged adults, but no meaningful associations were found for older adults. Additionally, no significant link was observed between dog walking and social cohesion among either age group. Future research can further improve the use of dog-based behavioural health interventions for fostering social capital.

\section{Data availability}

Please contact the corresponding author for requests to access anonymised data.

Received: 2 December 2020; Accepted: 6 May 2021;

Published online: 25 May 2021

\section{References}

American Pet Products Association (2018) APPA National Pet Owners Survey 2017-2018. APPA, Greenwich, CT

Barcelos AM, Kargas N, Maltby J, Hall S, Mills DS (2020) A framework for understanding how activities associated with dog ownership relate to human well-being. Sci Rep 10:1-12

Bassett E, Moore S (2013) Mental health and social capital: Social capital as a promising initiative to improving the mental health of communities. In: Rodriguez-Morales AJ (ed) Current Topics in Public Health. IntechOpen, pp 685-707

Canadian Veterinary Medical Association (2011) Canada's pet wellness report. Canadian Veterinary Medical Association, Ottawa, ON
Christian H, Wood L, Nathan A, Kawachi I, Houghton S, Martin K, Mccune S (2016) The association between dog walking, physical activityand owner's perceptions of safety: cross-sectional evidence from the US and Australia. BMC public health $16: 1010$

Christian H, Bauman A, Epping JN, Levine GN, McCormack G, Rhodes RE, Richards E, Rock M, Westgarth C (2018) Encouraging dog walking for health promotion and disease prevention. Am J Lifestyle Med 12:233-243

Christian HE, McCormack GR, Evenson, KR, Maitland C (2017) Dog walking, walking. In: Corinne Mulley KG, Ding Ding (ed.) Walking: connecting sustainable transport with health (transport and sustainability). Emerald Publishing Limited

Corder K, Ogilvie D, van Sluijs EM (2009) Invited commentary: physical activity over the life course-whose behavior changes, when, and why? Am J Epidemiol 170:1078-1081

Curl AL, Bibbo J, Johnson RA (2016) Dog walking, the human-animal bond and older adults' physical health. Gerontologist 57:930-939

Curl AL, Bibbo J, Johnson RA (2020) Neighborhood engagement, dogs, and life satisfaction in older adulthood. J Appl Gerontol. https://doi.org/10.1177/ 0733464820953725

Cutt H, Giles-Corti B, Knuiman M, Burke V (2007) Dog ownership, health and physical activity: a critical review of the literature. Health Place 13:261-272

Cutt HE, Giles-Corti B, Knuiman MW, Pikora TJ (2008) Physical activity behavior of dog owners: development and reliability of the Dogs and Physical Activity (DAPA) tool. J Phys Act Health 5:S73-S89

Degeling C, Rock M (2013) 'It was not just a walking experience': reflections on the role of care in dog-walking. Health Promot Int 28:397-406

Fujisawa Y, Hamano T, Takegawa S (2009) Social capital and perceived health in Japan: an ecological and multilevel analysis. Soc Sci Med 69:500-505

Graham TM, Glover TD (2014) On the fence: Dog parks in the (un) leashing of community and social capital. Leis Sci 36:217-234

Growth from Knowledge (2016). Pet ownership global GfK survey. GfK

Hanibuchi T, Kondo K, Nakaya T, Shirai K, Hirai H, Kawachi I (2012) Does walkable mean sociable? neighborhood determinants of social capital among older adults in Japan. Health Place 18:229-239

Hui Gan GZ, Hill A-M, Yeung P, Keesing S, Netto JA (2019) Pet ownership and its influence on mental health in older adults. Aging Ment Health 24:1605-1612

Kawachi I (2010) Social capital and health. In: Bird C, Fremont A, Timmermans S, Conrad P (Ed.) Handbook of medical sociology 6th edn. Vanderbilt University Press, Nashville, pp. 18-32

Kawachi I, Subramanian SV, Kim D (2008) Social capital and health, Social capital and health. Springer, pp. 1-26

Koohsari MJ, Nakaya T, McCormack GR, Shibata A, Ishii K, Yasunaga A, Liao Y, Oka K (2020a) Dog-walking in dense compact areas: the role of neighbourhood built environment. Health Place 61:102242

Koohsari MJ, Nakaya T, Oka K (2018) Activity-friendly built environments in a super-aged society, Japan: current challenges and toward a research agenda. Int J Environ Res Public Health 15:2054

Koohsari MJ, Shibata A, Ishii K, Kurosawa S, Yasunaga A, Hanibuchi T, Nakaya T, McCormack GR, Oka K (2020b) Dog ownership and adults' objectivelyassessed sedentary behaviour and physical activity. Sci Rep 10:1-7

Liao Y, Huang P-H, Chen Y-L, Hsueh M-C, Chang S-H (2018) Dog ownership, dog walking, and leisure-time walking among Taiwanese metropolitan and nonmetropolitan older adults. BMC Geriatr 18:1-7

Mackenbach JD, Lakerveld J, van Lenthe FJ, Kawachi I, McKee M, Rutter H, Glonti K, Compernolle S, De Bourdeaudhuij I et al. (2016) Neighbourhood social capital: measurement issues and associations with health outcomes. Obes Rev 17:96-107

McDonald S, Mair CA(2010) Social capital across the life course: age and gendered patterns of network resources. Sociological Forum 25:335-359. https://doi. org/10.1111/j.1573-7861.2010.01179.x 
McNicholas J, Collis GM (2000) Dogs as catalysts for social interactions: robustness of the effect. Br J Psychol 91:61-70

Moore S, Haines V, Hawe P, Shiell A (2006) Lost in translation: a genealogy of the "social capital" concept in public health. J Epidemiol Community Health 60:729-734

Mubanga M, Byberg L, Nowak C, Egenvall A, Magnusson PK, Ingelsson E, Fall T (2017) Dog ownership and the risk of cardiovascular disease and death-a nationwide cohort study. Sci Rep 7:15821

Muckenhuber J, Stronegger WJ, Freidl W (2013) Social capital affects the health of older people more strongly than that of younger people. Ageing Soc 33:853

Mujahid MS, Diez Roux AV, Morenoff JD, Raghunathan T (2007) Assessing the measurement properties of neighborhood scales: from psychometrics to ecometrics. Am J Epidemiol 165:858-867

Nyqvist F, Victor CR, Forsman AK, Cattan M (2016) The association between social capital and loneliness in different age groups: a population-based study in Western Finland. BMC Public Health 16:1-8

Oka K, Shibata A (2009) Dog ownership and health-related physical activity among Japanese adults. J Phys Act Health 6:412-418

Oka K, Shibata A (2012) Prevalence and correlates of dog walking among Japanese dog owners. J Phys Act Health 9:786-793

Pan H (2018) Social capital and life satisfaction across older rural Chinese groups: does age matter? Social work 63:75-84

Pooley JA, Cohen L, Pike LT (2005) Can sense of community inform social capital? Soc Sc J 42:71-79

Power ER (2013) Dogs and practices of community and neighboring. Anthrozoos 26:579-591

Riumallo-Herl CJ, Kawachi I, Avendano M (2014) Social capital, mental health and biomarkers in Chile: assessing the effects of social capital in a middle-income country. Soc Sci Med 105:47-58

Rock MJ, Adams CL, Degeling C, Massolo A, McCormack GR (2015) Policies on pets for healthy cities: a conceptual framework. Health Promot Int 30:976-986

Rodgers J, Valuev AV, Hswen Y, Subramanian S (2019) Social capital and physical health: an updated review of the literature for 2007-2018. Soc Sci Med 236:112360

Rogers J, Hart LA, Boltz RP (1993) The role of pet dogs in casual conversations of elderly adults. J Soc Psychol 133:265-277

Shibata A, Oka K, Inoue S, Christian H, Kitabatake Y, Shimomitsu T (2012) Physical activity of Japanese older adults who own and walk dogs. Am J Prev Med 43:429-433

Spire Research and Consulting (2018) The pet economy boom in Asia. Spire Research and Consulting

Toohey A, McCormack G, Doyle-Baker P, Adams C, Rock M (2013) Dog-walking and sense of community in neighborhoods: implications for promoting regular physical activity in adults 50 years and older. Health Place 22:75-81

Toohey AM, Rock MJ (2011) Unleashing their potential: a critical realist scoping review of the influence of dogs on physical activity for dog-owners and nonowners. Int J Behav Nutr 8:1-9

Wang H, Schlesinger M, Wang H, Hsiao WC (2009) The flip-side of social capital: the distinctive influences of trust and mistrust on health in rural China. Soc Sci Med 68:133-142

Wells DL (2004) The facilitation of social interactions by domestic dogs. Anthrozoos 17:340-352

Westgarth C, Christley RM, Christian HE (2014) How might we increase physical activity through dog walking?: a comprehensive review of dog walking correlates. Int J Behav Nutr Phys Act 11:83

Westgarth C, Christley RM, Jewell C, German AJ, Boddy LM, Christian HE (2019) Dog owners are more likely to meet physical activity guidelines than people without a dog: an investigation of the association between dog ownership and physical activity levels in a UK community. Sci Rep 9:1-10

Wood L, Christian H (2011) Dog walking as a catalyst for strengthening the social fabric of the community. In: Johnson R, Beck A, McCune S (eds) The health benefits of dog walking for pets and people. Purdue University Press. pp. 51-74

Wood L, Giles-Corti B, Bulsara M (2005) The pet connection: pets as a conduit for social capital? Soc Sci Med 61:1159-1173

Wood L, Martin K, Christian H, Houghton S, Kawachi I, Vallesi S, McCune S (2017) Social capital and pet ownership-a tale of four cities. SSM Popul Health 3:442-447

Wood L, Martin K, Christian H, Nathan A, Lauritsen C, Houghton S, Kawachi I, McCune S (2015) The pet factor-companion animals as a conduit for getting to know people, friendship formation and social support. PLoS ONE 10: e0122085

Xue X, Reed WR, Menclova A (2020) Social capital and health: a meta-analysis. J Health Econ 72:102317

Yip W, Subramanian SV, Mitchell AD, Lee DT, Wang J, Kawachi I (2007) Does social capital enhance health and well-being? evidence from rural China. Soc Sci Med 64:35-49

\section{Acknowledgements}

Nakaya was supported by the JSPS KAKENHI (\#20H00040). McCormack is supported by a Canadian Institutes of Health Research Foundations Scheme Grant (FDN-154331) Oka is supported by a Grant-in-Aid for Scientific Research (No. 20H04113) from the Japan Society for the Promotion of Science.

\section{Competing interests}

The authors declare no competing interests.

\section{Additional information}

Correspondence and requests for materials should be addressed to M.J.K.

Reprints and permission information is available at http://www.nature.com/reprints

Publisher's note Springer Nature remains neutral with regard to jurisdictional claims in published maps and institutional affiliations.

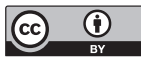

Open Access This article is licensed under a Creative Commons Attribution 4.0 International License, which permits use, sharing, adaptation, distribution and reproduction in any medium or format, as long as you give appropriate credit to the original author(s) and the source, provide a link to the Creative Commons license, and indicate if changes were made. The images or other third party material in this article are included in the article's Creative Commons license, unles indicated otherwise in a credit line to the material. If material is not included in the article's Creative Commons license and your intended use is not permitted by statutory regulation or exceeds the permitted use, you will need to obtain permission directly from the copyright holder. To view a copy of this license, visit http://creativecommons.org/ licenses/by/4.0/

(c) The Author(s) 2021 